\title{
Balkanologie
}

Balkanologie Revue d'études pluridisciplinaires

Vol. $16 n^{\circ} 1 \mid 2021$

Au-delà de la "route des Balkans ": mondes sociaux des circulations

\section{Atdhe Hetemi, Student Movements for the Republic of Kosovo 1968, 1981 and 1997}

Cham, Palgrave Macmillan, 2020

\section{Gentian Çitaku}

\section{OpenEdition \\ Journals}

\section{Édition électronique}

URL : https://journals.openedition.org/balkanologie/3180

DOI : 10.4000/balkanologie.3180

ISSN : 1965-0582

\section{Éditeur}

Association française d'études sur les Balkans (Afebalk)

\section{Référence électronique}

Gentian Çitaku, «Atdhe Hetemi, Student Movements for the Republic of Kosovo 1968, 1981 and 1997 »,

Balkanologie [En ligne], Vol. 16 n 1 | 2021, mis en ligne le 01 juin 2021, consulté le 03 octobre 2021.

URL : http://journals.openedition.org/balkanologie/3180; DOI : https://doi.org/10.4000/balkanologie. 3180

Ce document a été généré automatiquement le 3 octobre 2021.

(c) Tous droits réservés 


\section{Atdhe Hetemi, Student Movements for the Republic of Kosovo 1968, 1981 and}

\section{7}

Cham, Palgrave Macmillan, 2020

\section{Gentian Çitaku}

\section{RÉFÉRENCE}

Hetemi, Atdhe, 2020, Student Movements for the Republic of Kosovo 1968, 1981 and 1997, Cham, Palgrave Macmillan, 2020, 273 pages, ISBN : 978-3-030-54952-7

1 Au sein de la Yougoslavie socialiste (1945-1991), composée de six républiques fédérées et de deux provinces autonomes, le statut de république n'a jamais été attribué au Kosovo. Dans la monographie issue de sa thèse, soutenue à l'Université de Gand (Belgique) en 2020, Atdhe Hetemi propose une analyse des causes et des conséquences de trois mobilisations estudiantines ayant eu lieu au Kosovo en 1968, 1981 et 1997, ainsi que de leur rôle dans la lutte indépendantiste, entre quêtes égalitariste et nationaliste. Il s'attelle à décrire le contexte et les conditions dans lesquels ces protestations ont eu lieu ainsi que leurs conséquences dans la vie politique au Kosovo, en Yougoslavie et en Albanie. Elles secouèrent ce qui était alors la province yougoslave autonome du Kosovo, les étudiants mobilisés réclamant d'abord en 1968 et 1981 le statut de république fédérée, puis l'indépendance complète dans le contexte géopolitique très différent des années 1997-1998. L'ouvrage, composé de six chapitres, commence par exposer le cadre théorique et le contexte sociopolitique général (chapitres 1 et 2) avant de reconstituer les trois moments de mobilisation (chapitres 3 à 6).

2 Le premier chapitre s'attache à décrire le contexte, le thème et la thèse (l'importance des mobilisations estudiantines dans le cheminement vers l'indépendance kosovare), ainsi que le cadre méthodologique. L'auteur propose une approche historique des mobilisations, s'appuyant en particulier sur les analyses de Charles Tilly à propos de 
l'importance des contextualisations historiques des mouvements sociaux. L'articulation entre l'État, l'Université de Prishtina et les étudiants constitue le fil rouge de l'ouvrage. L'auteur s'appuie sur des sources variées : outre des ouvrages scientifiques et certains témoignages, il utilise les archives du Parti communiste, celles des organes de presse, en particulier les journaux Rilindja, Zëri i Popullit, Zëri i Rinisë, Flaka e Vëllazërimit, Borba, Novosti, Politika, Tanjug Vreme, Jedinstvo, les archives des ministères des Affaires étrangères du Kosovo, de Serbie et d'Albanie ainsi que la littérature secondaire. Enfin, il a interviewé une trentaine de témoins et d'acteurs : anciens dissidents ayant vécu dans l'illégalité, anciens étudiants (participants et organisateurs des manifestations), responsables politiques, académiciens, anciens fonctionnaires des services secrets et autres témoins.

3 Le second chapitre revient sur la perception des Albanais en Yougoslavie, en particulier en Serbie. Hetemi y met en exergue le portrait très négatif de l'Albanais dressé par différents auteurs, médias et intellectuels serbes à partir de la fin du XIX ${ }^{e}$ siècle, en s'appuyant sur les analyses de l'orientalisme proposées par Edward Saïd et sur celles du balkanisme élaborées par Maria Todorova. Par la mise en avant de caractéristiques comme l'arriération, le clanisme, la brutalité et l'incapacité à gouverner, il rappelle que les Albanais y sont à la fois devenus "l'autre national " (le non-slave) et «l'autre religieux» (le musulman). Pour l'auteur, cette représentation était à l'époque principalement motivée par les prétentions territoriales de la Serbie sur des régions majoritairement albanophones (Kosovo, nord de l'Albanie et ouest de la Macédoine). D'autres raisons pourraient également être invoquées pour expliquer cette hostilité à l'islam et aux Albanais, liées aux références constantes dans l'historiographie serbe au très long "joug ottoman » et à l'exaltation du Moyen Âge pré-ottoman. Quoiqu'il en soit, c'est au début de la période communiste que l'enseignement en albanais a été officialisé pour la première fois au Kosovo. On comprend alors la valorisation et le poids politique accordé au savoir, véritable préservateur et catalyseur de culture nationale, dans une région sous-développée et massivement analphabète jusqu'au lendemain de la Seconde Guerre mondiale.

4 Les quatre chapitres suivants sont consacrés aux trois mobilisations estudiantines. Deux ont eu lieu pendant la période communiste alors que la dernière a eu lieu à quelques mois de l'éclatement des affrontements armés au Kosovo, lorsque la majeure partie de la Yougoslavie était déjà disloquée. Chaque mobilisation, concernant une génération étudiante spécifique, a eu une portée et des conséquences différentes, dans un contexte intra-yougoslave et international différent. Pour chacune, l'auteur suit une structure logique et efficace, en s'intéressant au contexte politique yougoslave et kosovar, aux préparatifs, aux acteurs, au déroulement et enfin à ses conséquences régionales et internationales. Le cadre géopolitique pris en compte est donc multidimensionnel. Ainsi, la protestation de 1968 a été en quelque sorte la moins dissidente et la plus fructueuse car, profitant d'un contexte intra-yougoslave favorable, l'élite politique kosovare aurait soutenu son déroulement. Celle de 1981, la plus violente et la plus importante de par son envergure, occupe le cœur de l'ouvrage (les chapitres 4 et 5 , le chapitre 5 étant entièrement dédié aux réactions ayant suivi la manifestation). Elle a eu des répercussions dans toute la Yougoslavie, avec la déclaration de l'état d'urgence au Kosovo. L'auteur pointe un certain nombre d'éléments passionnants qui indiqueraient que les étudiants n'étaient pas du tout les seuls organisateurs de ce mouvement contestataire, d'apparence spontanée, allant jusqu'à suggérer que les services secrets soviétiques, yougoslaves et albanais y ont 
participé. Il laisse la question ouverte, la réponse se trouvant selon lui dans des archives officielles russes, serbes et albanaises encore inaccessibles. Enfin, la dernière manifestation estudiantine s'est déroulée dans un contexte très différent, en octobre 1997. Toute la société albanaise du Kosovo luttait alors pour l'indépendance dans un contexte d'oppression étatique ouverte.

5 Hetemi expose les deux pôles politiques dominant la société kosovare pendant la période communiste : les «titistes », partisans de "l'unité-fraternité » dans un cadre yougoslave, représentés par l'élite politique kosovare formellement loyale au régime et les « enveristes », nationalistes albanais pro-Enver Hoxha dont le but était l'union des régions albanophones de Yougoslavie à l'Albanie. Ces derniers étaient connus sous le nom de "groupes illégaux", certains émigrés albanais en Europe occidentale en faisaient partie. Le poids politique prépondérant de l'Université albanophone de Prishtina y est aussi bien mis en lumière : elle comptait de nombreux étudiants en sciences humaines, car l'enseignement de l'histoire et de la linguistique comportait des aspects relevant davantage du nationalisme que de la science (en particulier, la rigidité avec laquelle étaient présentées les théories sur l'origine des Albanais, l'ancienneté de leur langue ainsi que le caractère continu du peuplement albanais au Kosovo depuis l'Antiquité).

6 L'auteur présente le processus générationnel des trois protestations, la précédente servant systématiquement de modèle à la suivante, dans un contexte géopolitique mouvant. Il analyse également les principales demandes des mouvements estudiantins. Les revendications des protestataires étaient égalitaristes: on réclame une université albanophone, de meilleures conditions universitaires, la fin de l'oppression policière sous Ranković (ministre de l'Intérieur à poigne, évincé en 1966), le statut de république fédérée (le célèbre slogan "Kosovo république »). Cependant, plusieurs slogans étaient nationalistes : «longue vie à l'Albanie », "vive Enver Hoxha », « nous sommes albanais et non yougoslaves ». Dans le contexte yougoslave, le nationalisme était une inspiration et un moteur contestataire, la spécificité linguistique albanaise constituait la base identitaire. L'auteur montre que les revendications ont gagné en maturité au fil du temps. Le nationalisme était davantage présent lors des deux premières manifestations. Cela s'explique par le pragmatisme, la maturité politique gagnée et le contexte géopolitique yougoslave. La dernière, celle d'octobre 1997, la moins connue des trois, est traitée dans le sixième chapitre. Loin de réclamer l'union du Kosovo à l'Albanie, elle a d'abord appelé au retour de l'enseignement supérieur en albanais, prohibé par le régime de Milošević, puis, à partir du début des affrontements armés en mars 1998, à l'indépendance du Kosovo. Bien organisées et pacifiques, ces contestations ont attiré l'attention de la diplomatie américaine. On pourrait regretter que, de la dislocation yougoslave, seule l'indépendance des républiques de Slovénie et de Croatie ainsi que la Conférence de Dayton soient évoquées, et non les très violentes guerres de BosnieHerzégovine et de Croatie (p. 203). La mention de ces atrocités aurait pourtant permis de mettre en perspective la violence du régime de Milošević et de faire comprendre au lecteur qu'une épée de Damoclès menaçait les Albanais kosovars dans les années 1990.

7 Ces critiques n'enlèvent rien à l'importance indéniable de la contribution de la monographie d'Atdhe Hetemi à un thème jusqu'alors négligé par la recherche universitaire: la contestation étudiante kosovare durant le $\mathrm{xx}^{\mathrm{e}}$ siècle. L'auteur démontre que la lutte pour la république du Kosovo qui aboutit en 2008 à la déclaration d'indépendance a été en grande partie menée et entretenue par les étudiants. Hetemi 
ouvre la voie à l'étude approfondie du rôle politique de l'Université de Prishtina au Kosovo ainsi que, plus généralement, à l'étude de l'articulation entre nationalisme et revendications sociales dans les contextes postsocialistes.

\section{AUTEURS}

\section{GENTIAN ÇITAKU}

Inalco (Paris)

gentian_citaku[at]hotmail.com 